See discussions, stats, and author profiles for this publication at: https://www.researchgate.net/publication/320388622

\title{
Emergency residential care settings: A model for service assessment and design
}

Article in Evaluation and Program Planning · October 2017

DOI: 10.1016/.j.evalprogplan.2017.10.008

CITATIONS

4 authors:

2. João Graça

University of Lisbon

20 PUBLICATIONS 150 CITATIONS

SEE PROFILE

Joana Nunes Patrício

ISCTE-Instituto Universitário de Lisboa

23 PUBLICATIONS 66 CITATIONS

SEE PROFILE
113

Maria Calheiros

University of Lisbon

105 PUBLICATIONS 305 CITATIONS

SEE PROFILE

Eunice Magalhães

ISCTE-Instituto Universitário de Lisboa

29 PUBLICATIONS 292 CITATIONS

SEE PROFILE

Some of the authors of this publication are also working on these related projects:

Parent-Child Interactions as a Source of Parent Cognition in the Context of Child Maltreatment View project

PHD in Social and Community Psychology - Decision making * Child protection View project 


\title{
Emergency residential care settings: A model for service assessment and design
}

\author{
João Graça $^{\mathrm{a}, \mathrm{b}, *}$, Maria Manuela Calheiros ${ }^{\mathrm{a}, \mathrm{c}}$, Joana Nunes Patrício ${ }^{\mathrm{a}}$, Eunice Vieira Magalhães ${ }^{\mathrm{a}}$ \\ a Instituto Universitário de Lisboa (ISCTE-IUL), CIS-IUL, Lisboa, Portugal \\ b Instituto de Ciências Sociais (ICS), Universidade de Lisboa, Portugal \\ c Centro de Investigação em Ciência Psicológica, Faculdade de Psicologia, Universidade de Lisboa, Portugal
}

\section{A R T I C L E I N F O}

\section{Keywords:}

Residential care

Evaluation and design

Service model

Emergency care

Children and youth

Process consultation

\begin{abstract}
A B S T R A C T
There have been calls for uncovering the "black box" of residential care services, with a particular need for research focusing on emergency care settings for children and youth in danger. In fact, the strikingly scant empirical attention that these settings have received so far contrasts with the role that they often play as gateway into the child welfare system. To answer these calls, this work presents and tests a framework for assessing a service model in residential emergency care. It comprises seven studies which address a set of different focal areas (e.g., service logic model; care experiences), informants (e.g., case records; staff; children/youth), and service components (e.g., case assessment/evaluation; intervention; placement/referral). Drawing on this process-consultation approach, the work proposes a set of key challenges for emergency residential care in terms of service improvement and development, and calls for further research targeting more care units and different types of residential care services. These findings offer a contribution to inform evidence-based practice and policy in service models of residential care.
\end{abstract}

\section{Introduction}

A number of reviews on children and youth services have been calling for more research and evaluation to inform evidence-based practice and policy in service models of residential care (BoelStudt \& Tobia, 2016; Carrà,2014; Souverein, Van der Helm, \& Stam, 2013). Residential care is often used as an umbrella term which may encompass many different service models and dimensions (e.g., goals, target population, length of stay, treatment approaches; BoelStudt \& Tobia, 2016; Butler \& McPherson，2007; James，2011; Lee, 2008), but solid evidence is lacking to show if these different service models actually work in achieving their goals (Harder \& Knorth, 2015; Knorth, Harder, Zandberg, \& Kendrick, 2008). Furthermore, to protect and promote the development of children and youth in care, it is necessary to know not only if these different service models work, but also how they work and, importantly, to know what works best for whom (Harder \& Knorth, 2015; James, 2011; Knorth et al., 2008). To allow for building such knowledge, a required first step is to describe the contents of care of what has been called the "black box" of the "residential intervention package" (Axford, Little, Morpeth, \& Weyts, 2005; James, 2011; Knorth et al., 2008).

Against this backdrop, one type of residential care service is in particular need of research, given the strikingly scant empirical attention that it has received so far - which contrasts with the role this service often plays as gateway into the child welfare system (cf. Hurley, Ingram, Czyz, Juliano, \&Wilson, 2006; Leon, Jhe Bai, Fuller, \& Busching, 2016). Specifically, we refer to emergency residential care settings for children and youth who are at risk or in danger. These settings offer temporary placement in group care, usually while a case assessment is underway and/or a more permanent placement is being planned (Leon et al., 2016; Oakes \& Freundlich, 2005). A small set of studies have explored how variables of the children associate with other variables such as placement, length of stay and subsequent referrals with regard to emergency care (e.g., Hurley et al., 2006; Koehn, Thompson, Authier, \& Bosco, 2001; Leon et al., 2016; Oakes \& Freundlich, 2005; Wattenberg, Luke, \& Cornelius, 2004), but no studies have yet offered a description and analysis of a service model (i.e., "contents of care") for this type of care. This goes against recommendations for researching specific interventions applied in residential care, to pave the way for an increased understanding of how different outcomes are achieved, instead of simply examining the outcomes that are achieved (Harder \& Knorth, 2015; Libby, Coen, Price, Silverman, \& Orton, 2005). Furthermore, this is a problem because it compromises the first step of building knowledge to inform evidence-

\footnotetext{
* Corresponding author at: Instituto Universitário de Lisboa (ISCTE-IUL), CIS-IUL, Lisboa, Portugal.

E-mail addresses: joao_daniel_graca@iscte.pt, joao.graca@outlook.com (J. Graça).
} 
based practice and policy in service models of residential care, specifically emergency care. The present work aims to offer a contribution to address this problem. It lays the foundations of a framework for assessing and designing a service model, with specific service components, to address the needs of children and youth entering in emergency group care. Additionally, it presents an assessment of these service components in an emergency care setting (i.e. emergency shelter) for children and youth, which will allow for building research-driven recommendations.

\subsection{Towards a service model of emergency care for children and youth - preliminary framework and conceptualization}

Given the paucity of research in the area, it is a challenging task to propose a framework for assessing a service model of emergency care for children and youth. Nevertheless, drawing from previous studies (e.g., Gershowitz \& MacFarlane, 1990; Libby et al., 2005; Liese, Anderson, \& Evans, 2004; Wattenberg et al., 2004), the legal dispositions that may frame this type of service (e.g., MTSS, 2006; ISS, 2010, s/d; Lei $\left.n^{\circ} 142 / 2015\right)$, and inputs from more established literatures in the area of child protection (e.g., Bentovim, Cox, Miller, \& Pizzey, 2009; Daniel, Wassel, \& Gilligan, 2011; Turney, Platt, Selwyn, \& Farmer, 2011), it is possible to advance a preliminary conceptualization with service components to guide a service assessment (Fig. 1).

The service component Crisis/emergency response refers to resources, activities and outputs which ensure the child's immediate safety and removal from danger, her emotional and behavioral stabilization, and the attempt to minimize the traumatic potential of the context or situation that triggered protective care. The component Case assessment/ evaluation refers to resources, activities and outputs which identify the needs and characteristics (i.e. risk and protective factors) of the child

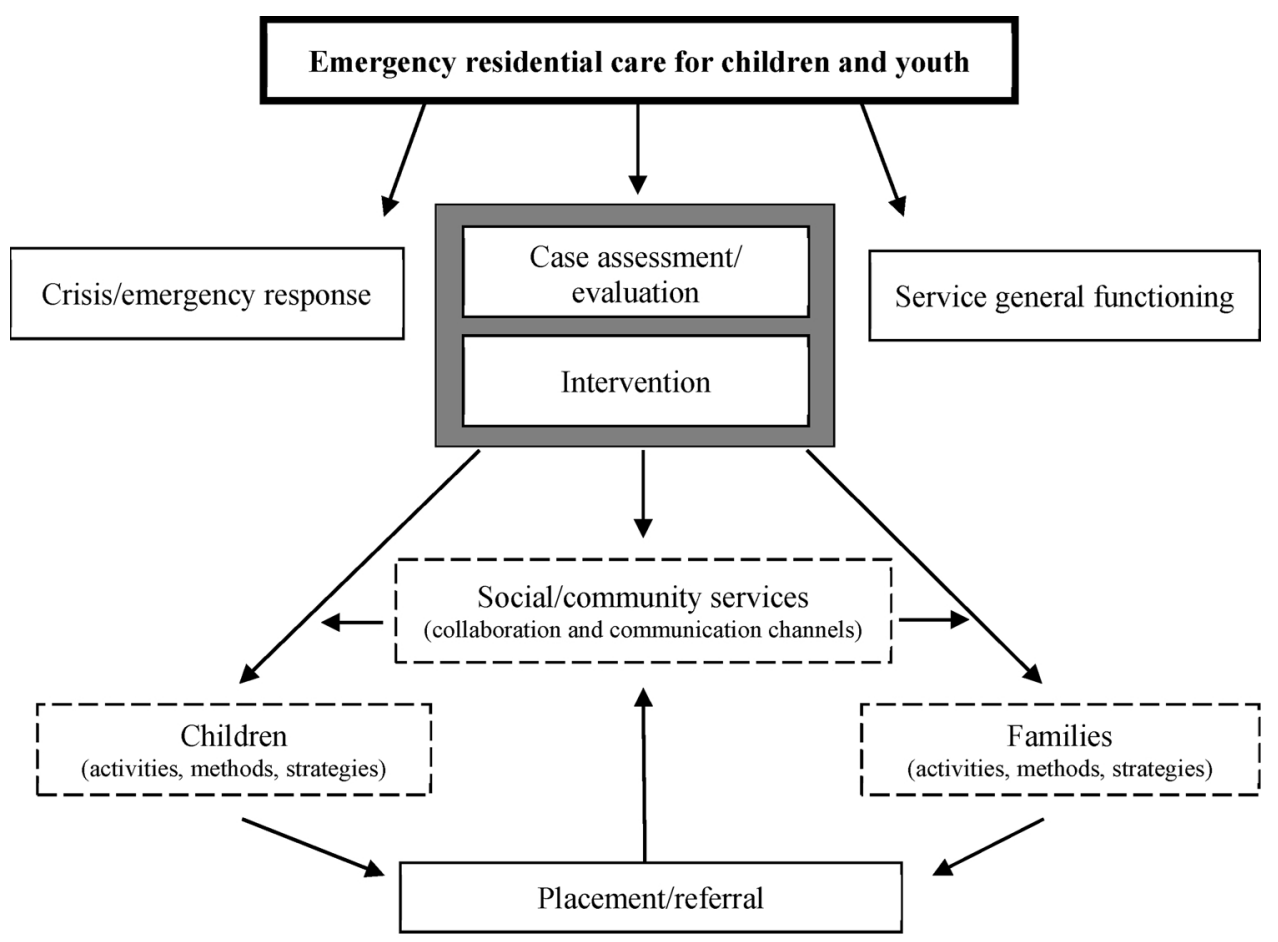

and her family. In turn, the component Intervention refers to resources, activities and outputs which activate and deliver an answer to the needs and characteristics identified with the child and the family. Both the components of Case assessment/evaluation and Intervention draw heavily on interinstitutional cooperation with other community services, and on the work that is done with the children/youth and with the families. The component Service general functioning refers to resources, activities and outputs to maintain a residential care facility at a domestic (vs. institutional) scale. Lastly, the service component Placement/referral includes the planning and implementation of the child/young person's placement (e.g., family reintegration; kinship care; foster care; residential care; adoption), and activating interinstitutional cooperation with other community services to ensure appropriate post-placement monitoring and support.

\subsection{Current work: general aims and overview}

This work aims to build knowledge to inform evidence-based practice and policy in service models of residential care, specifically emergency care. As a first step in this direction, it offers a framework for assessing a service model which addresses the needs of children and youth in an emergency care setting. Drawing on this framework and a process consultation approach, this work presents in seven studies a service description and assessment of an emergency residential care setting for children and youth (i.e., emergency shelter) in Portugal. These studies are organized under three focal areas (i.e., overview of the service logic model and population; assessing specific service features; care experiences), with several informants (i.e., case records; service documentation; staff; children and youth) to assess the different framework components (i.e., crisis/emergency response; case assessment/evaluation; intervention; service general functioning; and
Fig. 1. Service model - preliminary framework and conceptualization.

Caption:

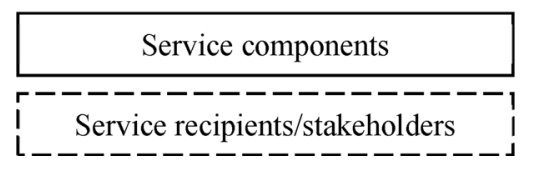


Table 1

Overview of the process consultation approach - focal areas, informants, studies, and framework components.

\begin{tabular}{|c|c|c|}
\hline Focal areas (informants) & Studies & Framework components \\
\hline $\begin{array}{l}\text { A. Initial overview of the target group characteristics and } \\
\text { service logic model (case records; staff) }\end{array}$ & $\begin{array}{l}\text { Study 1: Service and target group general } \\
\text { description } \\
\text { Study 2: Overview of the service logic model - } \\
\text { inputs, activities and outcomes }\end{array}$ & $\begin{array}{l}\text { Crisis/emergency response; Case assessment/evaluation; } \\
\text { Intervention; Placement/referral } \\
\text { Crisis/emergency response; Case assessment/evaluation; } \\
\text { Intervention; General functioning; Placement/referral }\end{array}$ \\
\hline $\begin{array}{l}\text { B. Assessing specific service features (service guidelines and } \\
\text { documentation; staff) }\end{array}$ & $\begin{array}{l}\text { Study 3: Document analysis and systematization } \\
\text { Study 4: Key inputs and activities in each } \\
\text { component } \\
\text { Study 5: Collaboration with social/community } \\
\text { services }\end{array}$ & $\begin{array}{l}\text { Crisis/emergency response; Case assessment/evaluation; } \\
\text { Intervention; General functioning; Placement/referral } \\
\text { Crisis/emergency response; Case assessment/evaluation; } \\
\text { Intervention; General functioning; Placement/referral } \\
\text { Crisis/emergency response; Case assessment/evaluation; } \\
\text { Intervention; General functioning; Placement/referral }\end{array}$ \\
\hline C. Assessing care experiences (children and youth; staff) & $\begin{array}{l}\text { Study 6: Participation, socioemotional climate, } \\
\text { and domestic scale } \\
\text { Study 7: Affective environment }\end{array}$ & $\begin{array}{l}\text { Intervention; General functioning } \\
\text { Intervention; General functioning }\end{array}$ \\
\hline
\end{tabular}

placement/referral). Table 1 shows an overview of the focal areas, informants, studies, and framework components.

\section{Overview of the target group characteristics and service logic model}

Logic models are seen as a fundamental tool for planning, evaluating and improving social services (e.g., Hawkins, Clinton-Sherrod, Irvin, Hart \& Russel, 2009). They emphasize a process approach that underlies any service or intervention, through a system which comprises a set of features and connections. Specifically, the logic model allows for systematically illustrating the relationships between the inputs of a given intervention, the activities that are delivered, and the outcomes or objectives that are expected. The inputs can be seen as comprising the set of resources (e.g., human; material; physical; community resources) that are available to the intervention, as well as the needs of the clients and contextual constraints. The activities include any processes and actions that are delivered as part of the intervention, with the aim of achieving a given outcome or objective. Lastly, the outcomes and objectives refer to any changes (e.g., behaviours; beliefs; skills; events) that are expected to occur as a result of delivering the intervention activities. Studies 1 and 2 aim to provide an initial overview of the needs and characteristics of the children and youth in this emergency care setting, service delivery, and a preliminary outline of the service logic model. These studies will draw on case records and the staff as informants.

\subsection{Study one: service and target group general description}

\subsubsection{Methods and procedures}

Data was collected with the Form for Assessing Children and Youth in Emergency Care, which was created for the purposes of this study, and comprises 86 items in four areas: a) personal information, admission and family characteristics (e.g., "date of admission"; "type of family"); b) intervention during emergency care (e.g., "family guidance in daily routines"); c) case assessment (e.g., "number of sessions for psychological assessment"); d) placement/referral (e.g., "date of child's placement"). The form includes nominal, ordinal, continuous, and open-ended response scales/fields, and was filled by the staff of the emergency shelter drawing on information on case records and staff meetings. Upon assessment, the shelter had been functioning for a period of around 16 months, thus the sample was comprised of the 17 children and youth that had been admitted and placed (i.e. already left shelter care) in that period of activity, providing a snapshot of the service from entrance to leaving emergency care.

\subsubsection{Main results}

2.1.2.1. Personal information, admission and family characteristics. The children/youth who had entered and left emergency care $(\mathrm{N}=17)$ were 3 to 15 years old $(\mathrm{M}=12$; $\mathrm{SD}=3.6), 11$ boys $(64.7 \%)$ and 6 girls (35.3\%), Portuguese (82.4\%), Guinean $(11.8 \%)$ or Brazilian $(5.9 \%)$. Upon admittance, the children/youth were referred by the child protection services (64.6\%), community services (11.8\%), schools (5.9\%), family members $(5.9 \%)$, social services $(5.9 \%)$, or health centres (5.9\%). The motives included neglect (76.5\%), school dropout (23.5\%), abandonment (11.8\%), maltreatment (11.8\%), child disruptive behaviour (5.9\%), and sexual abuse (5.9\%); and $35.3 \%$ of the cases had more than one motive for referral.

Families were identified as single-parent (47.1\%), re-constructed (23.5\%), nuclear $(17.6 \%)$ or extended (11.8\%). All children/youth had siblings (aged 2 to 31 years; $M=10.4, S D=6.8$ ), there was information on the mothers in $70.6 \%$ of the cases (aged 30 to 40; $\mathrm{M}=34.9, \mathrm{SD}=3.5$ ), and the fathers in $58.8 \%$ (aged 29 to 59; $\mathrm{M}=40.7, \mathrm{SD}=9.9$ ). Known family problems included lack of parenting skills (82.4\%), parental emotional instability (23.5\%), substance abuse $(17.6 \%)$, domestic violence $(11.8 \%)$, socioeconomic problems (11.8\%), and serious health conditions (5.9\%); and $41.2 \%$ of the families were multi-problematic (i.e., identified as having two or more problems).

2.1.2.2. Intervention during stay in emergency care. Intervention (with the child and/or family; delivered by the shelter and/or other services) may refer to five areas: housing/daily-living, socioeconomic situation, health, family relationships, and education. An overview of Table 2 suggests that available interventions were focused mainly on attempting to address socioeconomic, health and educational needs, but not needs on housing/daily-living and family relationships. It also suggests that in most cases where an intervention was offered, it was also accepted by the child/family.

2.1.2.3. Case assessment. Indicators with regard to case assessment refer to five topics: gathering of initial information, physical and mental health assessment, context/family-household and relationships assessment, and diagnostic report (with placement/referral proposal). Gathering of initial information (i.e., children/youth and families' current and previous general situation) lasted the equivalent of 0.13 to 1.97 months $(\mathrm{M}=0.8 ; \mathrm{SD}=0.47)$. The physical health assessment was completed for all cases, starting from the equivalent of 0.2 to 14.33 months $(\mathrm{M}=2.99$; $\mathrm{SD}=4.51)$ upon admittance, and lasting 0 to 16.93 months ( $\mathrm{M}=3.68$; $\mathrm{SD}=5.22)$, with a total of 1 to 13 appointments/ examinations $(\mathrm{M}=3.88 ; \mathrm{SD}=2.78)$. The mental health assessment was not completed in around half of the cases (52.9\%); in the remaining cases, the assessment started from 0 to 1.63 months $(\mathrm{M}=0.38$; $\mathrm{SD}=1.44)$ upon admittance, and lasted 0.73 to 3.33 months $(\mathrm{M}=1.71 ; \mathrm{SD}=0.83)$, with a total of 1 to 8 sessions $(\mathrm{M}=5.18$; $\mathrm{SD}=1.25)$. The context/family-household and relationships assessment was completed for almost all cases (94.1\%), starting from 
Table 2

Intervention during stay in emergency care (\%).

\begin{tabular}{|c|c|c|c|c|c|c|}
\hline Interventions/activities & Needed but not offered & Offered and accepted & Offered and rejected & Already being delivered & Non Applic. & No info. \\
\hline \multicolumn{7}{|l|}{ Housing/daily-living } \\
\hline Family guidance in daily routines & 35.3 & 17.6 & 0 & 0 & 35.3 & 11.8 \\
\hline Family guidance in the living space & 47.1 & 0 & 0 & 0 & 41.2 & 11.8 \\
\hline Direct intervention in the living space & 35.3 & 0 & 0 & 5.9 & 41.2 & 17.7 \\
\hline \multicolumn{7}{|l|}{ Socioeconomic situation } \\
\hline Financial support & 0 & 17.6 & 0 & 5.9 & 52.9 & 23.5 \\
\hline Guidance/assistance for social benefits & 0 & 11.8 & 0 & 0 & 35.3 & 52.9 \\
\hline Employability/work support & 5.9 & 23.6 & 5.9 & 29.4 & 23.5 & 11.8 \\
\hline \multicolumn{7}{|l|}{ Health (families) } \\
\hline Physical health care/assistance & 0 & 0 & 0 & 76.5 & 11.8 & 11.8 \\
\hline Mental health care/assistance & 0 & 17.6 & 0 & 11.8 & 64.7 & 5.9 \\
\hline Specific behavioral intervention & 0 & 17.6 & 0 & 0 & 76.5 & 5.9 \\
\hline Medication & 0 & 0 & 5.9 & 5.9 & 76.5 & 11.8 \\
\hline \multicolumn{7}{|l|}{ Health (children/youth) } \\
\hline Physical health care/assistance & 0 & 0 & 0 & 88.2 & 0 & 11.8 \\
\hline Mental health care/assistance & 0 & 11.8 & 11.8 & 23.5 & 29.4 & 23.5 \\
\hline Specific behavioral intervention & 0 & 23.5 & 5.9 & 0 & 64.7 & 5.9 \\
\hline Medication & 0 & 5.9 & 11.8 & 11.8 & 64.7 & 5.9 \\
\hline \multicolumn{7}{|l|}{ Family relationships } \\
\hline Parental support/intervention & 41.2 & 0 & 0 & 0 & 58.8 & 0 \\
\hline Family relationships support/intervention & 64.7 & 23.5 & 5.9 & 0 & 5.9 & 0 \\
\hline \multicolumn{7}{|l|}{ Education (children/youth) } \\
\hline Educational support & 0 & 47 & 0 & 29.4 & 17.6 & 5.9 \\
\hline Special education & 0 & 17.7 & 0 & 17.6 & 58.8 & 5.9 \\
\hline
\end{tabular}

0 to 0.97 months $(\mathrm{M}=0.11 ; \mathrm{SD}=0.58)$ upon admittance, and lasting 0.73 to 3.27 months $(M=1.84$; $S D=0.83)$, with a total of 1 to 7 home visits $(\mathrm{M}=3.81$; $\mathrm{SD}=1.72)$ and 0 to 38 family visits in the shelter $(\mathrm{M}=16.75 ; \mathrm{SD}=13.29)$. Lastly, the diagnostic report was completed for almost all cases (94.1\%); it was ready from 2.10 to 5.73 months $(\mathrm{M}=3.15 ; \mathrm{SD}=2.05)$ upon admittance, with a total of 1 to 3 internal case study meetings $(\mathrm{M}=2.47 ; \mathrm{SD}=0.62)$ and 1 to 3 meetings with other services - e.g., local child-protection services - $(\mathrm{M}=2.12$; $\mathrm{SD}=0.6$ ).

2.1.2.4. Placement/referral. Indicators with regard to placement/ referral show that more than half of the children/youth $(58.8 \%)$ were placed on a longer-term residential care facility, $23.5 \%$ were reintegrated in the family of origin, and $17.6 \%$ were placed in kinship care. There was separation of siblings in $17.6 \%$ of the cases. Total time of stay in emergency care ranged from 1.8 to 14.73 months $(\mathrm{M}=6.43 ; \mathrm{SD}=3.54)$.

2.2. Study two: overview of the service logic model - inputs, activities and outcomes

\subsubsection{Methods and procedures}

A semi-structured focus-group was conducted with the staff of the emergency care facility $(\mathrm{N}=10$; aged $25-55, \mathrm{M}=38.9, \mathrm{SD}=8.6$; $70 \%$ female). The discussion lasted nearly two hours $(1 \mathrm{~h} 52 \mathrm{~m})$ and was structured around three broad topics: needs and resources of the service; general functioning of emergency shelter and children/youth needs; perceived results and effectiveness. All participants were briefed, gave their consent to record the session, and were assured that their identity would not be disclosed when analysing and reporting the data. The recording was transcribed verbatim and the data were analysed and framed under the logic model framework (i.e., inputs; activities; outcomes), using thematic analysis with the steps proposed by Braun and Clarke (2006): (1) familiarizing with the data - repeated reading and hearing of the data in an active way (i.e. initial search for meanings and patterns); (2) generating initial codes - relevant semantic features within the data were coded and patterns were noted; (3) searching for categories - codes were sorted and collated into potential categories to capture and summarize participants' perspectives, with the lens of the logic model framework; (4) reviewing categories - categories were reviewed and revised against the data, and framed under the logic model framework; (5) defining categories - the essence of each category (i.e. the core meaning and pattern of the data it captured) was identified. The whole transcript was systematically analysed and coded; however, to favour parsimony and representativeness, categories with a minimum of ten quotes are considered and presented here. Specific quotations which were considered vivid and representative examples were selected to illustrate the findings.

\subsubsection{Main results}

A total of 477 quotes were framed under the logic model general framework: Inputs $(\mathrm{N}=335 ; 70.2 \%)$, Activities $(\mathrm{N}=111 ; 23.2 \%)$ and Outcomes $(\mathrm{N}=31 ; 6.5 \%)$.

2.2.2.1. Inputs. The area referring to Inputs includes quotes about Resources and Needs.

2.2.2.1.1. Resources $(N=56)$. The staff highlighted the quality and availability of some the stakeholders in the interinstitutional network, such as the courts and legal services, local councils, and social services (e.g., "Our relationship with the courts has been very positive so far"). They also mentioned the quality, qualifications and resilience of the human resources (e.g., "This team has a high capacity-. This capacity to adapt (...) since the beginning, it has to do with our competence as professionals"); and a set of evaluation and intervention resources such as event logs and calendars of activities (e.g., "There is a document that we have to fill in, which is important for [the psychologist]").

2.2.2.1.2. Needs $(N=279)$. As for the Needs, the staff mentioned a set of shortcomings in the child protection system, such as problems with the existing legislation, lack of services to address specific mental health needs, and lack/ineffectiveness of local family intervention/ follow-up teams (e.g., "It is often easier to send the child to residential care than trying to promote family reintegration, because there is no support in the community to sustain this [reintegration] with the child"). The staff also mentioned a set of needs of the shelter with regard to structuring resources and procedures (such as guidelines and procedures to the contents of care of the shelter; follow-up/placement evaluation; meeting admission criteria), instruments and case assessments (such as lack of instruments; timing of assessments), and managing risk factors and behaviours of the children/youth and families (such as emotional instability; difficulties in obtaining 
cooperation) (e.g., "[The assessment] is subjective, very subjective. [...] We need instruments that are practical and useful"). Lastly, the staff mentioned several challenges in working in liaison with community partners, particularly with regard to some schools and some health care services (e.g., "[the local schools] are anything but our partners").

2.2.2.2. Activities. The area referring to Activities includes quotes about Assessment and intervention, Placement/referral, and Service general functioning.

2.2.2.2.1. Assessment and intervention $(N=59)$. The staff mentioned a flexible and informal environment as an intervention strategy, to allow for establishing closeness while meeting the different needs of the children and youth in the shelter (e.g., "We try to [continuously] gather information, and keep adapting the procedures to the knowledge we have on each child and each situation"). Against this background of flexibility, they also mentioned a diverse set of activities with the children/youth such as play and recreational moments, establishing rules and predictability, and building a sense of emotional security (e.g., "[We address] the issues of affect and security-."). Additionally, case assessment and report was also mentioned as comprising several but not very structured activities to evaluate the needs and risk factors of the children/youth and families (e.g., "[Establishing] an individual development plan, [...] knowing the child, the needs of the family, [...] the needs that we can observe").

2.2.2.2.2. Placement/referral $(N=22)$. The staff also identified a set of activities with regard to placement/referral, which included making contacts, gathering information for making the placement as swiftly as possible - prioritizing family reintegration or kinship care -, and also informal attempts of post-placement monitoring and follow-up (e.g., "Our goal is not to make many placements in residential care, [...] we try our outmost to find alternatives [to residential care]").

2.2.2.2.3. Service general functioning $(N=19)$. Activities referring to the service general functioning included the overall management, sharing and articulation between staff members, ensuring regular updates and maintaining everyday routines (e.g., "[To share] if [the child] had any problems, such as sitting at the table, eating-.")

2.2.2.3. Outcomes. The area referring to Outcomes includes quotes about Outcomes to the staff/service $(\mathrm{N}=17)$ and Outcomes to the children/youth $(\mathrm{N}=14)$.

2.2.2.3.1. Outcomes to the staff/service $(N=17)$. In the outcomes to the staff/service, the staff mentioned that the overall sum of needs and challenges taken together (i.e., needs of the shelter, shortcomings in the child protection system, challenges in articulating with community partners) caused feelings of adversity, exhaustion and frustration (e.g., "These issues wear out the team, [...] feeling that our work is not being delivered as we want it to be [...], this is very stressful").

2.2.2.3.2. Outcomes to the children/youth $(N=14)$. Notwithstanding, the staff mentioned that the general wellbeing and protection of the children/youth was being ensured, and that overall the shelter was being able to meet their general needs (e.g., "I think that the shelter does meet the needs of the children, [...] the overall results are rather positive so far").

\section{Assessing specific service features}

Studies 1 and 2 allowed for providing an initial overview of the needs and characteristics of the children and youth in shelter care, and a preliminary outline of the service logic model (Fig. 2).

Following a process centred approach, studies 3,4 and 5 aim to provide a more thorough and in-depth assessment of each service component, and identify key areas and activities of collaboration that are in need of improvements to ensure effective delivery of each service component (Fig. 1). These studies will draw on service guidelines/ documentation and the staff as informants.

\subsection{Study three: document analysis and systematization}

\subsubsection{Methods and procedures}

The documents/guidelines that support the shelter activity (i.e., three documents/guidelines: internal regulations, guide of procedures, information booklet) were analysed using thematic analysis with the steps proposed by Braun and Clarke (2006), following the same procedures of study 2, but with two levels of analysis. In the first level, categories were framed under the framework for assessing and designing the service model (i.e. crisis/emergency response; case assessment/evaluation; intervention; service general functioning; and placement/referral). In the second level, they were framed under the logic model framework, within each service model component (e.g., quotes for inputs, activities, objectives within the crisis/emergency response component). Again, to favour parsimony and representativeness, categories with a minimum of ten quotes are considered and presented here. Specific quotations which were considered vivid and representative examples were selected to illustrate the findings.

\subsubsection{Main results}

A total of 556 quotes were framed under the service model framework: Crisis/emergency response ( $\mathrm{N}=42 ; 7.6 \%)$, Case assessment/ evaluation ( $\mathrm{N}=87 ; 15.6 \%)$, Intervention ( $\mathrm{N}=142 ; 25.5 \%)$, Service general functioning $(\mathrm{N}=264 ; 47.5 \%)$, and Placement/referral $(\mathrm{N}=22 ; 3.9 \%)$.

\subsubsection{Crisis/emergency response}

3.1.2.1.1. Inputs $(N=21)$. In the guiding documents, the quotes that can be framed as inputs in the component crisis/emergency response referred to the situation of danger from which the child/ youth is removed from before admission, the need for an immediate protective response, and the shortage of such services in the protection system (e.g., "[...] current or imminent danger for the child's life or integrity").

3.1.2.1.2. Activities $(N=11)$. Activities framed in this component included the act and procedures of admission, such as interagency articulation, receiving the child, and providing immediate integration and emotional support (e.g., "[...] providing care with special attention in the moments of admission and integration in shelter").

3.1.2.1.3. Objectives $(N=10)$. Service objectives in the guiding documents that can be framed in this component referred to adequately delivering a protective response which meets the child's immediate, basic security needs (e.g., "[...] to safeguard the child from [harm and] danger").

\subsubsection{Case assessment/evaluation}

3.1.2.2.1. Inputs $(N=25)$. Inputs for the component of case assessment/evaluation included a set of instruments - cognitive and personality tests - , record sheets, contexts and procedures to guide the assessment (e.g., "[...] using instruments validated or created by the team").

3.1.2.2.2. Activities $(N=32)$. Activities framed in this component referred to the act of assessing both the children/youth and the family context/relationships (e.g., "The child health assessment should be conducted as soon as possible, upon admission").

3.1.2.2.3. Objectives $(N=30)$. Quotes in the guiding documents that can be framed as objectives in this component included assessing the children/youth and families in several areas of functioning and development - although these areas are usually not made specific, particularly with regard to family functioning and relationships -, and to provide evidence which informs a placement/referral decision as swiftly as possible ("[...] to know the [psychological] functioning of the child [...] in the different emotional, relational, and learning dimensions").

\subsubsection{Intervention}

3.1.2.3.1. Inputs $(N=28)$. Inputs framed in this component included the outcomes of case assessment/evaluation as informing the 


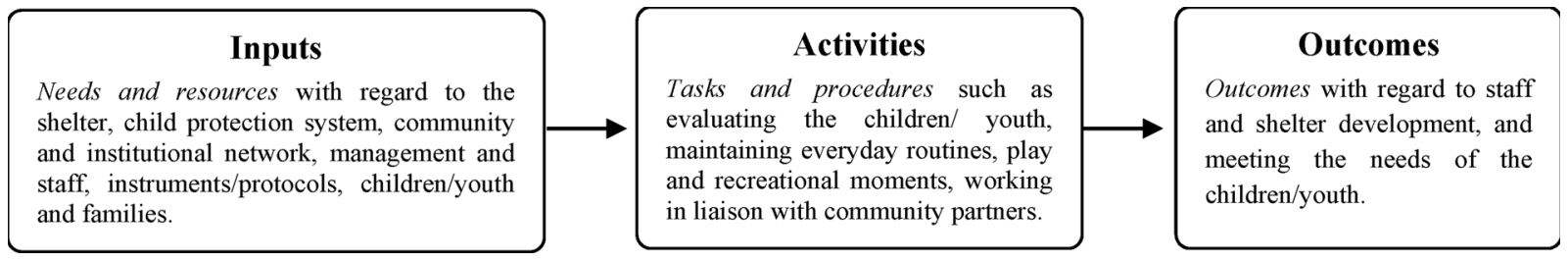

Fig. 2. Preliminary outline of the service logic model from study 2 .

intervention, and the focus in the children/youth as centre of the intervention, with a multidisciplinary and systemic approach, referring both to the shelter and to other community/local services (e.g., "[The intervention is] based on the conclusions drawn in the assessment").

3.1.2.3.2. Activities $(N=97)$. Activities for the intervention component largely referred to interventions with the children/youth in the shelter, such as establishing routines and self-care behaviours, promoting a therapeutic and protective environment, providing emotional and educational support, ensuring health care whenever necessary, and offering opportunities for recreational, cultural and sports activities (e.g., "[Establishing routines] as a pedagogical and structuring practice, which promotes a sense of security [and] predictability [...]"). There were also quotes referring to intervention with the families, such as promoting regular visits and contacts with the children/youth whenever possible, and developing parenting skills (e.g., "Maintaining regular contact with the families and others with whom the child has an affective relationship").

3.1.2.3.3. Objectives $(N=16)$. Quotes that can be framed as objectives in this component referred to promoting the health and well-being of the children/youth in care, their personal and social development, and support family reintegration ("[Intervention] to promote integration in the family whenever possible").

\subsubsection{Service general functioning}

3.1.2.4.1. Inputs $(N=49)$. Quotes in the guiding documents that can be framed as inputs in this component broadly referred to the facilities - which include several bathrooms, bedrooms, a living room, a multipurpose room, a kitchen, two offices -, and the human resources of the shelter - multidisciplinary team comprising psychology, social service, social education, jurisconsultation (e.g., "[...] five educators, one of which as coordinator").

3.1.2.4.2. Activities $(N=201)$. Activities framed in the component of service general functioning range from formal coordination and resource management, general work meetings, dealing with offenses and disciplinary measures, monitoring and supervision, training and qualification, functional contents, and general norms and procedures (e.g., "Elaborating a holiday map for the staff, [...] managing and proposing day offs and holidays in accordance with the needs of the shelter").

3.1.2.4.3. Objectives $(N=14)$. Quotes referring to the objectives in this component included ensuring proper work conditions to the team, the quality of care, and the general safety/wellbeing of the children and youth during their stay (e.g., "To provide a positive work environment, and suitable hygiene and safety conditions").

\subsubsection{Placement/referral}

3.1.2.5.1. Activities $(N=11)$. Quotes in the guiding documents referring to activities in this component included procedures for discharge/placement - family reintegration/kinship care, foster care, residential care, or adoption (e.g., "When [family reintegration] is not possible, [...] placement in a foster family or [referral to] adoption").

3.1.2.5.2. Objectives $(N=10)$. Objectives framed in this component were to deliver a placement/referral in accordance with the best interest of the child/youth, prioritizing family reintegration whenever possible ("[Placement decision] which meets the best interest of the child").

\subsection{Study four: key inputs and activities in each service component}

\subsubsection{Methods and procedures}

Three semi-structured interviews were conducted with key elements of the staff of the shelter - psychologist, social worker, educator coordinator - to gain more perspective into the key inputs and activities in each service component. Participants $(\mathrm{N}=3)$ were briefed, gave their consent to record the interviews, and were assured that their identity would not be disclosed when analysing and reporting the data. The interviews lasted 83 to $105 \mathrm{~min}$ and were structured in accordance to the framework for the service model. Recordings were transcribed verbatim and the data were analysed using the same procedures as the previous studies, following the steps proposed by Braun and Clarke (2006) and two levels of analysis - first, matching categories to the framework for assessing and designing the service model; second, framing them under "inputs" and "activities" from the logic model framework, within each service model component. Again, to favour parsimony, areas/categories with a minimum of ten quotes are considered and presented here, and quotations which were considered vivid and representative examples were selected to illustrate the findings.

\subsubsection{Main results}

A total of 743 quotes were framed under the service model framework: Crisis/emergency response ( $\mathrm{N}=153 ; 20.6 \%)$, Case assessment/ evaluation ( $\mathrm{N}=234$; 31.5\%), Intervention $(\mathrm{N}=114 ; 15.3 \%)$, Service general functioning $(\mathrm{N}=148 ; 19.9 \%)$, and Placement/referral $(\mathrm{N}=94 ; 12.7 \%)$.

\subsubsection{Crisis/emergency response}

3.2.2.1.1. Inputs $(N=63)$. Inputs mentioned for this component referred mainly to the challenges and constraints experienced by the staff upon entrance of the children/youth. In spite of having appropriate physical resources to receive the child/referring services/ family in the moment of admission, the team often struggled with lacking/misleading/erroneous information about the case, which they felt might compromise their ability to deliver a proper reply in terms of immediate emotional and behavioral support (e.g., "[The information] is frequently insufficient [...] or wrong"). Another key issue was the initial stance of the families, often hostile or suspicious, which added further challenges in adequately responding to the emotional distress of both the child and the family, and sometimes feelings of threat to the safety of the staff (e.g., "[They arrive] angry with us, because someone has to take with all this anger, [...] it's as if we were the ones who took their child away from them").

3.2.2.1.2. Activities $(N=90)$. Activities mentioned in this component referred mainly to involving the family immediately upon the child's entrance, presenting the shelter, the team members, disclosing and discussing the motives for referral/admission, and ensuring the child's safety to the family (e.g., "When the families arrive here for the first time, we tell them why [the child is in care] in the first contact"). Another main activity is providing immediate emotional and behavioral support to child, with active listening, reflecting and paraphrasing, and assisting in emotional regulation, with a flexible approach depending on the characteristics of the child and family (e.g., "[We] create a [relational] environment which is as securing as possible, in a situation that is very traumatic"). 


\subsubsection{Case assessment/evaluation}

3.2.2.2.1. Inputs $(N=110)$. Inputs in this component were mainly focused on the resources for assessing children/youth and their families, such as observation grids, interviewing scripts, projective and development/personality tests, multidisciplinary perspectives integrating inputs from different members of the staff, and data from other services such as child psychiatry consultation, when available (e.g., "We also have the Ecomap [to be used] with the family"). However, constraints were mentioned with regard to a lack of methods and tests/instruments to assess specific dimensions and needs of the children/youth, families, and child-parent relationships, an overlap in the roles of the psychologist, social worker and educators in the service functional content, and a lack of privacy in the physical spaces used for assessment/evaluation (e.g., "We don't have [...] instruments for assessing the families").

3.2.2.2.2. Activities $(N=124)$. There were three broad sets of activities in this component. The first referred to general tasks such as gathering available information and contacting local services with a history or connection to the child/family (e.g., "Sometimes we have meetings with the school of origin, [when there are issues] at the school level"). The second set included tasks to assess the children/youth, such as observing the child's routines and adaptation to the shelter, performing psychological acts, and arranging/attending medical appointments ("[...] concerning mental health-. We make an assessment"). Lastly, the third set included tasks to assess the family, referring mostly to home visits and observation of the family interaction with the child ("[...] we always try to make visits without the child and [also] with the child, when he/she [is allowed to go] home").

\subsubsection{Intervention}

3.2.2.3.1. Inputs $(N=30)$. In the intervention component, inputs referred mainly to difficulties in providing individual and personalised contents of care/intervention to each child, due to heavy schedules, overlaps in the service functional content, extended age range of the children/youth in the shelter, and the short duration or their stay (e.g., "So, starting a psychotherapeutic process knowing that it will soon have to be interrupted, because the child will change residence-. It doesn't make much sense").

3.2.2.3.2. Activities $(N=84)$. There were two main sets of activities in this component. The first referred to activities with the children/youth, which included play, sports and recreational activities, group dynamics, establishing rules/routines, providing educational support, and referrals to interventions outside of the shelter (e.g., "[Helping with the] homework, [...] we have study time after dinner"). The second set referred to activities with the families, which included providing opportunities for the families to maintain contact with the children/youth, and referrals which provide opportunities for therapy/ intervention in specific needs of the family (e.g., [...] the father has problems with alcohol, we have made several attempts [...] for him to be receptive for treatment").

\subsubsection{Service general functioning}

3.2.2.4.1. Inputs $(N=96)$. Inputs in this component were focused on the characteristics, quality and commitment of the human resources of the shelter (e.g., "[We are always] very open, so in face of adversity, any setbacks-. We're here to get around it and don't turn our backs to it"). However, needs and constraints were also mentioned, mainly with regard to a lack of external supervision and consultation, inadequacy of some material resources such as children/youth clothing, lack of personnel during weekends, and overall lack of service functional structure and formal care guidelines/procedures (e.g., "[Sometimes] it's not easy to work like this, on the grounds of informality").

3.2.2.4.2. Activities $(N=52)$. Activities in this component largely referred to sharing information and managing resources, with an emphasis on human resources, balancing the definition of roles and functional content with the requirements of shared tasks, responsibilities, and joint decision making - with attention also in maintaining a good working and living environment in the shelter ("[...] we [meet regularly and] keep sharing our opinions").

\subsubsection{Placement/referral}

3.2.2.5.1. Inputs $(N=80)$. Inputs in this component included a set of principles/criteria and needs/constraints with regard to placement/ referral. The principles/criteria highlighted the safety, protection and best interest of the children/youth - prioritizing family reintegration when possible -, the quality of the relationships and living environment of the family, and the evidence gathered during case assessment/evaluation (e.g., "There can be no doubt if the family is [or isn't] an abusive family"). In turn, needs and constraints mostly referred to concerns with lack of follow-up and post-placement monitoring, and with a perceived lack of quality of care in many residential care facilities (e.g., "It would be important [to have a follow-up], for instance after 12 months, to see how the family is going").

3.2.2.5.2. Activities $(N=14)$. Activities in the component of placement/referral included contacting with other services, outlining and analysing all the information gathered, and weighting prospective risk and protective factors in the different possibilities of placement/ referral for each case (e.g., "If they're placed in residential care, what usually happens is that [...] I forward my report to the team that will follow the case, and there's always a psychologist in the team").

\subsection{Study five: collaboration with social/community services}

\subsubsection{Methods and procedures}

Data was collected with the Form for Assessing Shelter Cooperation with Social/Community Services, which was created for the purposes of this study drawing on a model for collaborative capacity (FosterFishman, Lounsbury, Jacobson, \& Allen, 2001), the Interagency Collaboration Scale (Dedrick \& Greenbaum, 2011), and dimensions for assessing social networks available in the literature (e.g., Scott, 2000). The form was filled by the shelter staff and comprises two sets of scales: a) Areas and Activities of Collaboration - the extent in which shelter services share with other services a set of inputs/resources and activities (17 items, 1-Not at all to 5-Very much response scale); and b) Collaboration Partners and Stakeholders - frequency, dependency, capacity to meet shelter collaboration needs (1-Never/Not at all to 5Always/Very much response scale) and existence of protocols (dichotomous yes-no response scale), for a set of 20 services/stakeholders/ institutions (e.g., health centres; hospitals; schools).

\subsubsection{Main results}

3.3.2.1. Areas and activities of collaboration. An overview of Table 3 suggests that the shelter had a set of shared inputs/resources and activities mainly with regard to activities with "clients" (i.e., case assessment and evaluation, developing plans for child and family intervention, service information), program development and evaluation (i.e., professional training and qualification, dissemination of the shelter's services/activities), and collaboration policies (i.e., case meetings, formal protocols). The following section provides increased insight into how the different partners and stakeholders address the shelter's collaboration needs.

3.3.2.2. Collaboration partners and stakeholders. With regard to frequency, the data did not allow for almost any differentiation, since there were high frequencies of contact and collaboration with almost all the partners/stakeholders assessed, with the exceptions of religious associations, the police, and job centres (Table 4).

However, drawing from data concerning dependency (i.e. the extent in which the shelter depends on each partner to achieve its outcomes) and capacity to meet the shelter collaboration needs (both also shown in Table 4), an index was calculated to identify the communication channels in greater need of improvement. The index subtracts values in 
Table 3

Descriptives for areas and activities of collaboration with external services.

\begin{tabular}{ll}
\hline Dimension & Value \\
\hline Physical and financial resources & $\mathrm{M}=1,75$ \\
Financial resources & 1 \\
Acquisition/payment of services & 4 \\
Physical space & 1 \\
Archives and information management & 1 \\
Program development and evaluation & $\mathrm{M}=3$ \\
Development of programs and services & 1 \\
Evaluation of programs and services & 3 \\
Professional training and qualification & 4 \\
Dissemination of the shelter's services/activities & 4 \\
Activities with "clients" & $\mathrm{M}=3,20$ \\
Case assessment and evaluation & 5 \\
Registries/forms for admission & 2 \\
Developing plans for child and family intervention & 4 \\
Participation in interinstitutional boards/panels & 1 \\
Service information & 4 \\
Collaboration policies & $\mathrm{M}=3$ \\
Case meetings & 4 \\
Non formal protocols & 2 \\
Formal protocols & 4 \\
Voluntary contractual relations & 2 \\
\hline
\end{tabular}

Note: response scale from 1-Never/Not at all to 5-Always/Very much response scale.

Table 4

Descriptives for collaboration with partners and stakeholders (Frequency, dependency, capacity to meet needs).

\begin{tabular}{llll}
\hline Partners/Stakeholders & Freq. & Dep. & Meet Needs \\
\hline Health centres & 5 & 5 & 2 \\
Hospitals & 5 & 5 & 3 \\
Parish councils & 4 & 1 & 2 \\
Cultural/recreational centres & 4 & 1 & 2 \\
Youth associations & 3 & 1 & 3 \\
Religious associations & 2 & 1 & 2 \\
Social services - central teams/services & 5 & 5 & 4 \\
Social services - local teams/services & 5 & 5 & 2 \\
Child protection services & 5 & 5 & 4 \\
Courts & 5 & 5 & 5 \\
Police & 2 & 1 & 4 \\
Job centres & 2 & 2 & 2 \\
Universities/training centres & 4 & 3 & 5 \\
Other residential care services & 4 & 4 & 2 \\
Schools (local) & 5 & 5 & 4 \\
Schools (non-local) & 5 & 5 & 2 \\
NGOs, third sector & 5 & 4 & 4 \\
City councils & 4 & 3 & 2 \\
Court technical support team & 5 & 5 & 5 \\
Local charity & 5 & 5 & 4 \\
Sity & &
\end{tabular}

Note: response scale from 1-Never/Not at all to 5-Always/Very much response scale.

capacity to meet needs to values in dependency, such that higher resulting values suggest a greater need for improvement (Fig. 3).

This illustrates how communication and collaboration channels with Health centres, Social services (local teams/services) and Schools (non-local) were in marked need for improvement. And, to a lesser extent, also Hospitals, Social services (central teams/services), Child protection services, Other residential care services, Schools (local), City councils, and the Local charity. Nevertheless, within this broad set of partners and stakeholders showing a need for improvement, the shelter had formal/established protocols for collaboration only with the Social services (central teams/services).

\section{Care experiences}

Studies 3, 4 and 5 allowed for providing a more thorough and indepth assessment of each service component. Studies 6 and 7 aim to complement this assessment and shed light into the experiences of care in the shelter. As target group of the shelter, it is important to know the concerns, perspectives and expectations of the children and youth with regard to their experience in care. We subscribe to the view that children and young people are in a unique position to convey their own experiences, and have the legitimate right to manifest their needs and concerns on the issues that affect their lives (Calheiros, Patrício, \& Graça, 2013; Cashmore, 2002; Clark \& Moss, 2001; UNCRC, 1989). Furthermore, the participation of direct stakeholders (e.g., children and youth; staff) in service assessment and design is important also for building tailored responses and to foster service effectiveness (e.g., Calheiros et al., 2013; McMillen, Auslander, Elze, White, \& Thompson, 2003; Teufel-Shone, Siyuja, Watahomigie, \& Irwin, 2006). Studies 6 and 7 will draw on children/youth in the shelter and the staff as informants, with a special focus on the perspectives of children/youth as experts in their own experience.

\subsection{Study six: participation, socioemotional climate, and domestic scale}

\subsubsection{Methods and procedures}

A semi-structured focus-group was conducted with the older residents ( $N=7,57 \%$ boys), aged $13-15$ years $(M=14$, $S D=1)$, who were in the shelter care facility for an average of 3.89 months $(\mathrm{SD}=3.3$; $\operatorname{Min}=1$, Max $=10)$. Consent for participating in the study was provided by the shelter administration in advance, and participants were briefed, gave their consent to record the discussion, and were assured that their identity would not be disclosed when analysing and reporting the data. The discussion lasted nearly one hour $(58 \mathrm{~m})$ and was structured as to explore their perceptions of the daily routines, and positive/negative experiences in the shelter. The recording was transcribed verbatim and the data were analysed using thematic analysis with the five steps proposed by Braun and Clarke (2006), following a bottom-up approach (i.e., collation of codes into potential categories was done using semantic criteria; Boyatzis, 1998). To favour parsimony and representativeness, categories with a minimum of ten quotes are considered and presented. Quotations which were considered vivid and representative examples were selected to illustrate the findings.

\subsubsection{Main results}

A total of 275 quotes were framed under three areas: Domestic scale and participation $(\mathrm{N}=110 ; 40 \%)$, Socioemotional climate $(\mathrm{N}=124$; $45.1 \%)$, and Improving life in the shelter ( $\mathrm{N}=41 ; 14.9 \%)$.

4.1.2.1. Domestic scale and participation. Indicators of domestic scale and participation referred mainly to quotes on the daily living routines of the children/youth in the shelter. The times and schedules in the shelter were identified by the participants as overall flexible and adjusted to the routines of the different residents (e.g., "On Mondays I can sleep a little longer because my classes also start later"). The children/youth also mentioned diversity in terms of food and eating, although sometimes there was food waste (e.g., "[The breakfast] is different, [we can have] bread or cereals). There was also rotation and sharing of household tasks such as setting the table, taking out the trash, helping with the laundry, and tidying the bedroom/living room (e.g., 'Each one of us has his day to set the table, take out the trash-.'). During day-time, while not in school the children/youth had overall freedom to be in their bedroom or living room, and older residents usually had more autonomy to meet friends or go for walks outside the shelter. (e.g., "I usually prefer to stay in my room, I stay there more often than here downstairs [in the living room]"). There were opportunities for playing and diverse recreational activities inside the shelter, and opportunities for enrolling and engaging in sports activities outside the shelter (e.g., "[...] volleyball, futsal, football [...]").

4.1.2.2. Socioemotional climate. Quotes on the socioemotional climate of the shelter referred mainly to the relationships between the residents, and between the residents and the staff. With regard to the residents, 


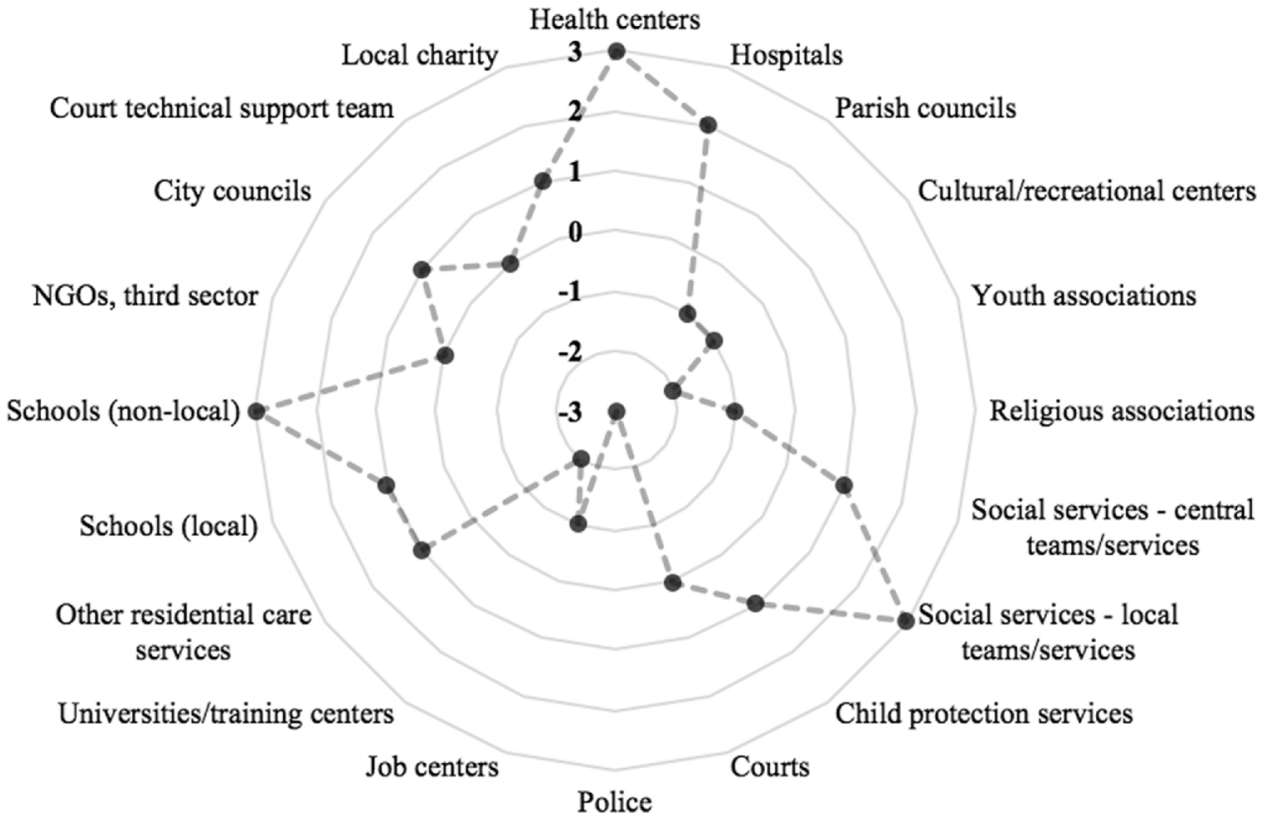

Fig. 3. Collaboration with partners and stakeholders - index of need for improvements. they mentioned that some children/youth previously in the shelter used to steal personal items and money from each other when they had the opportunity, which resulted in a general climate of suspicion and insecurity. However, the general consensus in the focus group was that in the current group of residents the feelings were mainly of mutual trust and support, even if there were occasional episodes of conflict and disagreement (e.g., "Now we do trust each other, but in the past, we didn't"). As for the relationships with the staff, the participants referred to relationships based on closeness, support and flexibility with some staff members, and distance and lack of trust with others (e.g., "Some of the educators are nicer [...], [they] help us"). Nevertheless, the general tone was that the children/youth had the possibility and opportunities to discuss any issues and negative feelings with the staff members, and that they felt heard.

4.1.2.3. Improving life in the shelter. As for suggestions for improving life in the shelter, the quotes referred mainly to providing more resources and activities for leisure and play - inside and outside the shelter - such as games, computers and bicycles (e.g., "We could have bicycles, to take some rides during weekends"). Participants also proposed more opportunities to customize the physical spaces of some of the areas of the shelter, and asked for more autonomy for the older residents (e.g., "We want to go out to meet our friends").

\subsection{Study seven: affective environment}

\subsubsection{Methods and procedures}

Data was collected with a questionnaire developed from the Diagram of Affective Quality Attributed to Environments (Russel \& Pratt, 1980). Drawing on responses from the children/youth and staff, the questionnaire allowed for measuring the affective qualities of each of the shelter's rooms/spaces and the shelter as a whole, along eight affective descriptors: unpleasant, distressing, arousing, exciting, pleasant, relaxing, sleepy, and gloomy (e.g., "As a whole, the shelter is PLEASANT"); in a scale ranging from 1-Not at all to 5-Very much. Participants were briefed, gave their consent to participate in the study, and anonymity was ensured. Two of the children were too young to adequately differentiate the descriptors -5 and 6 years respectively - thus the sample comprised: children $(\mathrm{N}=10$; aged $8-15$ years, $\mathrm{M}=12.2$, $\mathrm{SD}=2.3$; $60 \%$ male; length of stay $1-16$ months, $M=5.3, S D=4.6$ ) and staff $(\mathrm{N}=10$; aged $25-55, \mathrm{M}=38.9, \mathrm{SD}=8.6 ; 70 \%$ female $)$.

\subsubsection{Main results}

As a whole, the affective quality attributed to the shelter environments fell under the positive valence of the axis unpleasant-pleasant, both for the children/youth and the staff, and broadly encompassed the qualities of arousing, exciting, pleasant, relaxing, and sleepy (see Fig. 4 for visual depictions and Table 5 for detailed descriptives). The rooms and spaces were assessed in ways that generally match their functional purpose and activities (e.g., bedroom qualified by the children/youth markedly as pleasant and relaxing; multipurpose room qualified markedly as pleasant, exciting and arousing), and the views of the children/youth and staff were mostly consonant and overlapped, with minor exceptions (e.g., kitchen). Also noteworthy is that all rooms/ spaces of the shelter, and the shelter as a whole, scored very low in the negative affective descriptors that were assessed by the children/youth (i.e., gloomy, unpleasant, and distressing), which reinforces the notion that their care experiences were overall positive with regard to the shelter affective environment.

\section{Discussion}

This work aimed to offer a contribution for informing evidencebased practice and policy in service models of residential care, specifically emergency care. It presented seven studies under a framework for assessing a service model which addresses the needs of children and youth in emergency residential care (see Fig. 1 and Table 1 for a global picture of the evaluation). Although emergency care settings have been recognized as an important part of the child protection and care system (Hurley et al., 2006; Leon et al., 2016), to our knowledge this is the first time that an in-depth assessment of such a service - drawing on multiple studies and several informants - is delivered.

This assessment allowed for highlighting a set of features in each service component (Fig. 1) that can be used to guide service improvement and further develop a service model. Specifically, in the service component referring to crisis/emergency response, the staff highlighted the importance of trying to involve the families and building a cooperative working relationship from the outset whenever possible, and providing immediate support to the child (studies 2 and 4). This is consistent with international recommendations (Council of Europe, 2005) focused on the need to involve families in the placement planning and monitoring. Specifically, the exercise of parental responsibilities and of contact between the children and their parents is 

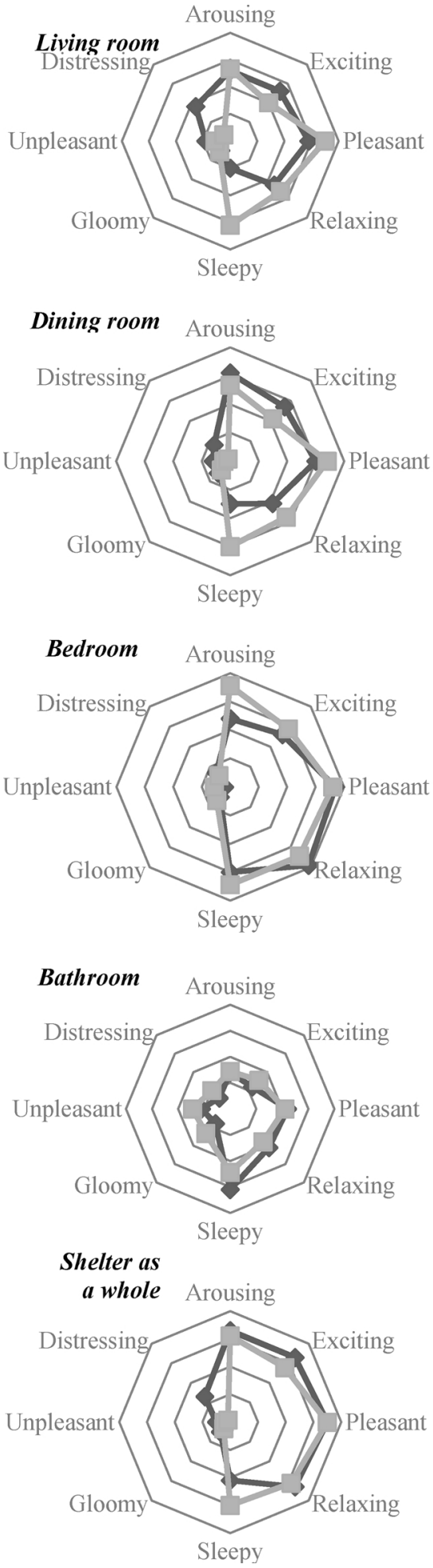

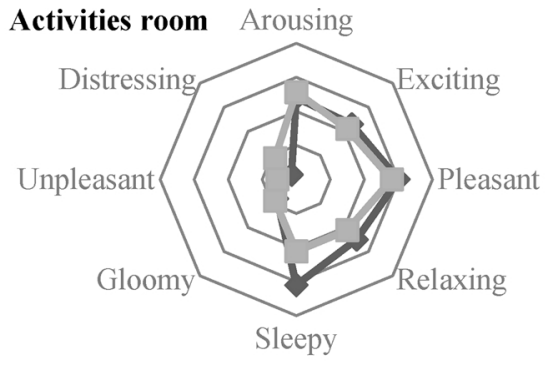

Fig. 4. Affective quality attributed to the shelter environments - visual depiction.
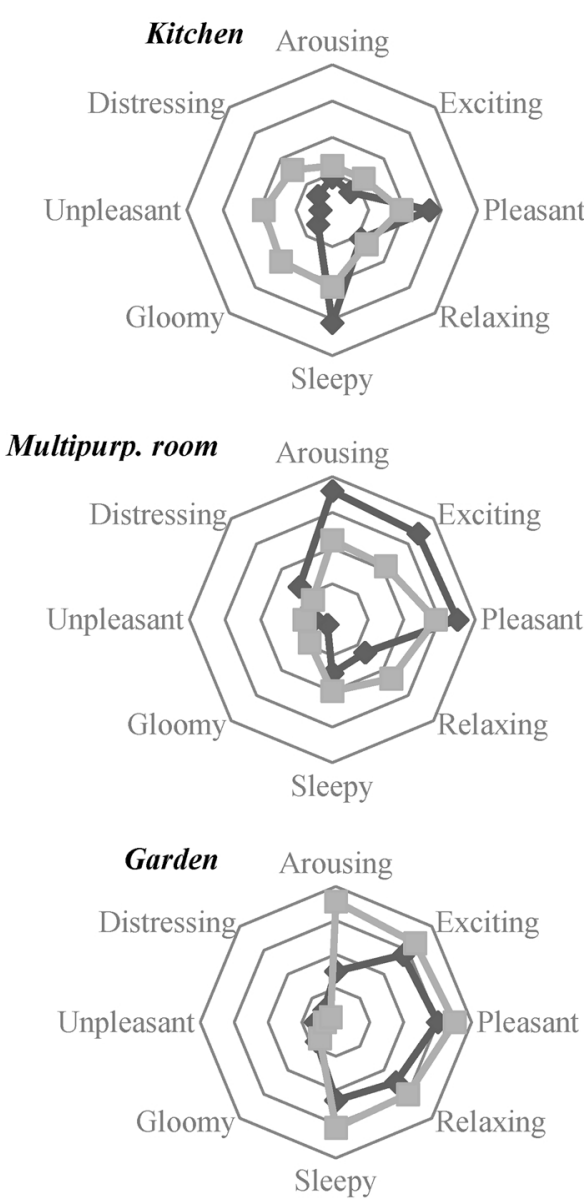

highlighted, together with the development of a care plan consistent with the child's needs (Council of Europe, 2005). The involvement of the children's families previously and during the care placement is recommended, particularly when family reunification is considered (Del Valle \& Zurita, 2015). Also, it is known that the entrance at the residential care setting may involve reactions of anger, denial and protest (Del Valle \& Zurita, 2015), which implies the immediate support from professionals in care to promote an adequate adaptation of the child. The inputs, activities and objectives referring to the component of crisis/emergency response seemed to be formally properly defined in the service guiding documents (study 3 ). Nevertheless, the staff qualified the referral information about the child as insufficient upon entrance, and the initial attitude of the families as often hostile (study 4). In fact, it could be difficult to engage these families in the intervention due to a number of factors, such as family's beliefs and expectations of rejection and criticism from professionals and social services. As such, it is crucial that professionals in this context are able to promote the family empowerment, through an empathic behaviour and establishing a trustful relationship (Garfat, 2007; Landy \& Menna, 2009). In the staff's experience, the lack of information about the children upon admittance 
Table 5

Affective quality attributed to the shelter environments - descriptives.

\begin{tabular}{|c|c|c|c|c|c|c|c|c|c|c|c|c|c|c|c|c|c|c|}
\hline & \multicolumn{2}{|c|}{ Living room } & \multicolumn{2}{|c|}{ Activities room } & \multicolumn{2}{|c|}{ Dining room } & \multicolumn{2}{|c|}{ Kitchen } & \multicolumn{2}{|c|}{ Bedroom } & \multicolumn{2}{|c|}{ Multipurp. room } & \multicolumn{2}{|c|}{ Bathroom } & \multicolumn{2}{|c|}{ Garden } & \multicolumn{2}{|c|}{ Shelter } \\
\hline & M & $\mathrm{SD}$ & M & $\mathrm{SD}$ & M & SD & M & $\mathrm{SD}$ & M & $\mathrm{SD}$ & $\mathrm{M}$ & SD & M & SD & M & SD & M & SD \\
\hline \multicolumn{19}{|c|}{ Children/Youth } \\
\hline Arousing & 3.6 & 1.3 & 3.4 & 1.6 & 4.1 & 1.1 & 1.9 & 1 & 3.4 & 1.8 & 4.6 & 0.7 & 2.4 & 1.7 & 2.5 & 1.6 & 4.3 & 1.5 \\
\hline Exciting & 3.6 & 1.6 & 3.3 & 1.8 & 3.7 & 1.6 & 1.7 & 1.1 & 3.6 & 1.8 & 4.4 & 0.7 & 2.2 & 1.6 & 3.8 & 1.6 & 4.3 & 1.5 \\
\hline Pleasant & 3.9 & 1.3 & 4 & 1.5 & 4 & 1.6 & 3.7 & 1.2 & 4.7 & 0.7 & 4.5 & 0.9 & 3.2 & 1.8 & 4 & 1.4 & 4.5 & 1.1 \\
\hline Relaxing & 3.3 & 1.6 & 3.5 & 1.8 & 3.1 & 1.6 & 2.1 & 1.7 & 4.9 & 0.3 & 2.3 & 1.7 & 3.1 & 1.7 & 3.5 & 1.8 & 4.3 & 1.3 \\
\hline Sleepy & 2 & 1.2 & 4.1 & 1.3 & 2.5 & 1.1 & 4.1 & 1.5 & 4 & 1.6 & 2.5 & 1.7 & 4.1 & 1.3 & 3.3 & 1.6 & 3.1 & 1.8 \\
\hline Gloomy & 1.5 & 1 & 1.8 & 1 & 1.6 & 1.1 & 1.3 & 0.9 & 1.5 & 0.9 & 1.2 & 0.4 & 1.8 & 1.1 & 1.8 & 1.1 & 1.5 & 0.7 \\
\hline Unpleasant & 1.9 & 0.9 & 1.5 & 0.7 & 1.6 & 0.7 & 1.3 & 0.7 & 1.2 & 0.4 & 1.5 & 0.9 & 2.1 & 1.5 & 1.6 & 1.1 & 1.5 & 0.9 \\
\hline Distressing & 2.8 & 1.8 & 1.2 & 0.4 & 1.8 & 1.4 & 1.6 & 1.3 & 1.7 & 1.5 & 2.3 & 1.8 & 1.6 & 1 & 1.5 & 0.7 & 2.3 & 1.6 \\
\hline \multicolumn{19}{|l|}{ Staff } \\
\hline Arousing & 3.7 & 1 & 3.6 & 1.6 & 3.7 & 0.7 & 2.2 & 1 & 4.6 & 0.5 & 3.2 & 1 & 2.4 & 1 & 4.6 & 0.5 & 4.1 & 0.8 \\
\hline Exciting & 3 & 1 & 3.1 & 0.3 & 3.1 & 0.9 & 2.2 & 1 & 3.9 & 0.9 & 3.1 & 0.9 & 2.6 & 1 & 4.3 & 0.7 & 3.8 & 0.7 \\
\hline Pleasant & 4.5 & 0.5 & 3.8 & 1.6 & 4.4 & 0.5 & 2.9 & 0.9 & 4.6 & 0.5 & 3.9 & 0.9 & 3.1 & 1.1 & 4.5 & 0.5 & 4.5 & 0.5 \\
\hline Relaxing & 3.6 & 0.5 & 3.1 & 0.8 & 3.8 & 0.7 & 2.3 & 0.9 & 4.4 & 0.5 & 3.3 & 1 & 2.8 & 1 & 4 & 0.7 & 4.1 & 0.6 \\
\hline Sleepy & 4.1 & 0.8 & 3.1 & 0.8 & 4 & 0.5 & 3.1 & 0.8 & 4.4 & 0.5 & 3 & 0.7 & 3.4 & 0.7 & 4.1 & 0.7 & 4 & 0.7 \\
\hline Gloomy & 1.6 & 0.7 & 1.9 & 1.1 & 1.4 & 0.7 & 3 & 1.3 & 1.7 & 0.7 & 1.9 & 1.1 & 2.3 & 0.9 & 1.7 & 0.9 & 1.3 & 0.5 \\
\hline Unpleasant & 1.6 & 0.7 & 1.6 & 0.7 & 1.2 & 0.4 & 2.9 & 1.6 & 1.6 & 0.7 & 1.8 & 1.1 & 2.4 & 1.1 & 1.3 & 0.5 & 1.2 & 0.4 \\
\hline Distressing & 1.3 & 0.5 & 1.9 & 1.1 & 1.1 & 0.3 & 2.6 & 1.4 & 1.6 & 0.7 & 1.8 & 1.1 & 2 & 1 & 1.2 & 0.4 & 1.1 & 0.3 \\
\hline
\end{tabular}

and the lack of cooperation of the families were two main features that might compromise the service ability to provide an adequate response in this component.

With regard to case assessment/evaluation, the general inputs and objectives were properly described in the service guiding documents, but the evaluation procedures seemed to be ill-defined (study 3 ). This lack of definition was reflected on the staff's perspectives about the insufficiency of clearly established focal areas, instruments and methods for evaluating the children/youth and their families (studies 2 and 4). Considering that these families tend to experience a greater number of risk factors and fewer protective ones, it is important to develop a detailed and comprehensively evaluation process, namely by using different tools and sources - e.g., interviews, observation, selfreport measures (Landy \& Menna, 2009). Furthermore, there were concerns about an overlap in terms of service functional content for the roles of psychologist, social worker and educator, in addition to insufficiencies of the physical space (i.e. ensuring privacy) which might compromise the evaluation (study 4). It is also noteworthy that an analysis of the service track (study 1) showed that the child mental health assessment was not completed in around half of the children that had already left the shelter. However, mental health is known to be a sensitive dimension in this population, given that these children tend to show greater mental health problems compared with children who are not in residential care (Fernández-Molina, Del Valle, Fuentes, Bernedo, \& Bravo, 2011). A proper clinical assessment of residential children and youth should be delivered, which should take place at the time of placement and again on a follow-up assessment. Taken together, these findings suggest that building capacity for case assessment/evaluation should be a priority in terms of service improvement in the shelter.

In the intervention component, service track records (study 1 ) indicated that interventions were activated mainly to address socioeconomic (e.g., financial assistance), health (e.g., mental health care) and educational needs (e.g., educational support). However, interventions to address existing needs in family relationships (e.g., parent/family support) and in housing/daily living (e.g., guidance in daily routines; restructuring of the living space) were often not offered. This contrasts with the notion that intervention in residential care should be provided based on child and family needs (e.g., needs related to the separation from home; maltreatment experiences) and also that the probability of success in a family reunification process is greater when there are positive family relationships (Del Valle \& Zurita, 2015; Garfat, 2007). Furthermore, the intervention with at-risk families should involve the promotion of competencies at different levels and domains, such as perceived self-efficacy and support, positive parent-child interactions, problem solving skills, emotional regulation, attributions and educational practices (Landy \& Menna, 2009). Psychological treatment plans should also be designed, implemented and evaluated. An important part of children and youth psychological and psychiatric intervention in residential care is to provide specialized support and also training for the staff (Jozefiak et al., 2016). To achieve these goals, however, the number of care workers must be sufficient and the resources for inter-disciplinary teamwork should be provided. A call for the professionalization of the welfare services for young people at risk of emotional, behavioral and family difficulties has been made in many countries (Hukkanen, Sourander, Bergroth, \& Piha, 1999). However, the mental health needs of youth at risk and in residential care continue to be a challenge for mental health and social services in Europe (e.g., Jozefiak et al., 2016; Magalhães \& Calheiros, 2017), and also in Portugal. In the overview of the service logic model (study 2), the staff also referred to a lack and ineffectiveness of local family intervention teams, which may help explain limitations in the intervention component. Critical needs with regard to collaboration with teams from local social services were also found when assessing collaboration and resources from the social network (study 5). However, when the case plan involves family reunification, it is crucial that the intervention includes a close coordination of professionals in care and in the community to avoid a lengthy placement (Del Valle, Bravo, Hernández, \& González, 2012). In the service guiding documents, it was possible to identify a set of inputs, activities and objectives to frame under the component of intervention (study 3). Children and youth's perspectives about their experience of care were consistently positive both in the assessment of participation, socioemotional climate and domestic scale (study 6) and in the assessment of the shelter affective environment (study 7). This is consistent with the need to promote effective participation processes in care, namely by allowing the child to access information, and promoting her involvement in daily-living and decision-making processes (Cashmore, 2002). However, the picture drawn from the staff as informants (studies 2 and 4) suggested that intervention activities were focused more in addressing the general needs of the children/youth in the shelter (e.g., providing recreation/occupation and fostering contact with families whenever possible), and less in providing tailored interventions to meet specific individual/family needs identified in the evaluation component. According to the staff, the main internal constrains in addressing more specific needs were related with heavy schedules and overlaps in service functional content, as well as with 
difficulties in addressing the extended age range of the children/youth in the shelter and the short duration of their stay. These results suggest that the intervention component should also be targeted as priority for service improvement in the shelter.

With regard to the component of service general functioning, the findings were consistent throughout the set of studies and informants in suggesting that the shelter was able to meet the general needs of the children/youth, providing a positive socioemotional climate and affective environment, and ensuring a domestic scale with respect for the children/youth's participation (studies 2, 6 and 7). This is consistent with international proposals which argue that residential care settings should replicate as much as possible a familiar environment with qualified professionals (Del Valle et al., 2012). General norms and procedures also appeared to be well established and coordinated (studies 2, 3 and 4). Furthermore, while the problems with an overlap of service functional content seemed to seriously compromise the components of assessment and intervention, according to the staff perspectives these problems were not so serious in affecting the activities and aims framed under the service general functioning (study 4). Additional needs and constraints were nonetheless identified, such as a lack of external supervision and consultation, and a lack of formal guidelines for care provision (i.e., existing formal guidelines were focused mostly on administrative and resource management procedures, and less on the contents of care to provide to children/youth). An adequate supervision, support and training for professionals is indeed crucial to develop an effective intervention in care and also to promote job satisfaction (Colton and Roberts, 2006; Van der Ploeg \& Scholte, 1998). Thus, as a whole, the component of service general functioning seemed to be relatively well delivered and consolidated in the shelter, but there was room for service development in this regard.

Lastly, in the placement/referral component, service track records showed that children/youth spent an average of 6 months in the shelter, most were placed on a longer-term residential care facility, and nearly $40 \%$ were reintegrated in the family of origin or placed in kinship care (study 1). This suggests that family reunification was not achieved in the majority of these cases, which calls for more investment in terms of community and family interventions that may foster successful processes of family reintegration. Although the staff and the guiding documents aimed at prioritizing family reintegration whenever possible (studies 2, 3 and 4), there was no systematic procedure to weight in all the evidence gathered in the assessment phase, and to outline risk and recovery prognostics for the final placement/referral decision. Importantly, the service did not include any follow-up and post-placement monitoring procedures to assess placement effectiveness. International guidelines also propose that it is important to provide significant support during family reunification by providing opportunities for restructuring family roles and norms, as well as an effective reintegration of the child (Del Valle \& Zurita, 2015). Thus, the placement/referral component should also be targeted for service improvement in the shelter.

Taking all findings in consideration, it is possible to summarize a set of key variables and challenges for emergency residential care in terms of service improvement and development (Table 6). Nevertheless, given the scope of the current work, it is necessary to highlight that this summary offers only a first step for further initiatives that create inputs for service development and improvement. In fact, this is a one-setting in-depth approach with a small sample size of participants (i.e., professionals and children/youth), which calls for further evidence with multi-settings approaches.

In spite of these limitations, this work offered a contribution to inform evidence-based practice and policy in service models of residential care. It presented and tested a framework for assessing a service model which addresses the needs of children and youth in residential emergency care, drawing on different focal areas (e.g., service logic model; care experiences), informants (e.g., case records; staff; children/youth), and service components (e.g., case assessment/evaluation;

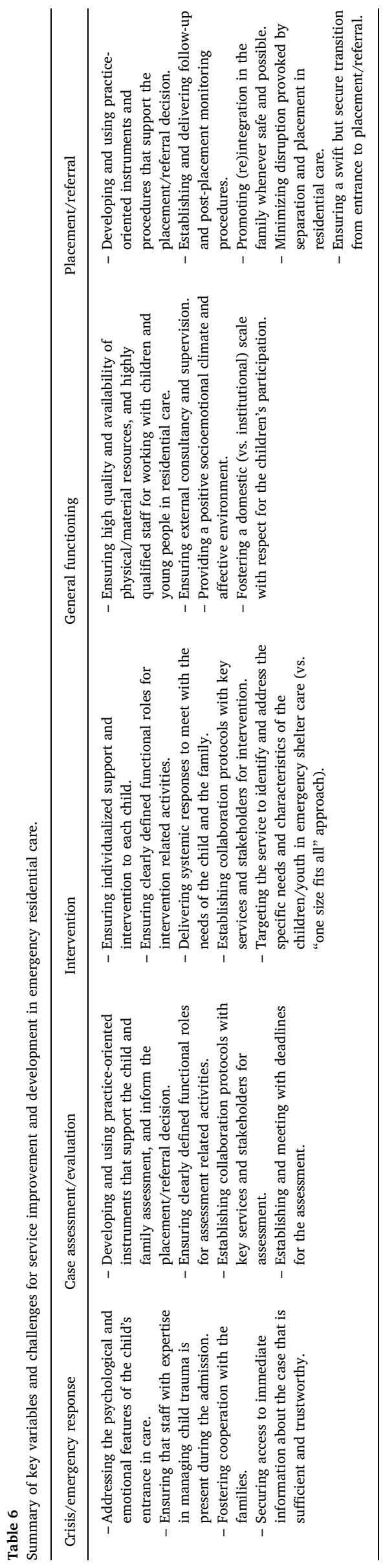


intervention; placement/referral). This directly addresses recent calls for uncovering the "black box" of residential care facilities, and shedding light into the contents of care that are actually provided to children and youth in these contexts (Axford et al., 2005; Harder \& Knorth, 2015; James, 2011; Knorth et al., 2008). The next step is to expand the scope of the evaluation with a focus on targeting more care units and also different types of residential care services, and afterwards designing, testing and disseminating service models to inform practice, research and policy in child care/protection.

\section{References}

Axford, N., Little, M., Morpeth, L., \& Weyts, A. (2005). Evaluating children's services: Recent conceptual and methodological developments. British Journal of Social Work, 35(1), 73-88.

Bentovim, A., Cox, A., Miller, L., \& Pizzey, S. (2009). Safeguarding children living with trauma and family violence: Evidence-based assessment, analysis and planning interventions. London: Jessica Kingsley Publishers.

Boel-Studt, S. M., \& Tobia, L. (2016). A review of trends, research, and recommendations for strengthening the evidence-base and quality of residential group care. Residential Treatment for Children \& Youth, 33(1), 13-35.

Boyatzis, R. (1998). Transforming qualitative information: Thematic analysis and code development. Thousand Oaks: Sage.

Braun, V., \& Clarke, V. (2006). Using thematic analysis in psychology. Qualitative Research in Psychology, 3(2), 77-101.

Butler, L. S., \& McPherson, P. M. (2007). Is residential treatment misunderstood? Journal of Child Family Studies, 16, 465-472.

Calheiros, M. M., Patrício, J. N., \& Graça, J. (2013). Staff and youth views on autonomy and emancipation from residential care: A participatory research study. Evaluation and Program Planning, 39, 57-66.

Carrà, E. (2014). Residential care: an effective response to out-of-home children and young people? Child \& Family Social Work, 19(3), 253-262.

Cashmore, J. (2002). Promoting the participation of children and young people in care. Child Abuse \& Neglect, 26(8), 837-847.

Clark, A., \& Moss, P. (2001). Listening to young children: The Mosaic approach. London: National Children's Bureau.

Colton, M., \& Roberts, S. (2006). The retention of residential group workers. International Journal of Child and Family Welfare, 9(3), 160-177.

Council of Europe (2005). Recommendation of the Committee of Ministers to member states on the rights of children living in residential institutions. Strasbourg: Council of Europe.

Daniel, B., Wassell, S., \& Gilligan, R. (2011). Child development for child care and protection workers. London: Jessica Kingsley Publishers.

Dedrick, R. F., \& Greenbaum, P. E. (2011). Multilevel confirmatory factor analysis of a scale measuring interagency collaboration of children's mental health agencies. Journal of Emotional and Behavioral Disorders, 19(1), 27-40.

Del Valle, J. F., \& Zurita, J. (2015). El acogimiento residencial en la protección a la infancia. Madrid: Ediciones Pirámide.

Del Valle, J. F., Bravo, A., Hernández, M., \& González, I. (2012). Estándares de calidad en acogimiento residencial. EQUAR. Madrid: Ministerio de Sanidad, Serviços Sociales e igualdade.

Fernández-Molina, M., Del Valle, J. F., Fuentes, M. J., Bernedo, M., \& Bravo, A. (2011) Problemas de conducta de los adolescentes en acogimiento pre adoptivo, residencial y con familia extensa. Psicothema, 23(1), 1-6.

Foster-Fishman, P. G., Berkowitz, S. L., Lounsbury, D. W., Jacobson, S., \& Allen, N. (2001). Building collaborative capacity in community coalitions: A review and integrative framework. American Journal of Community Psychology, 29(2), 241-261.

Garfat, T. (2007). Who are we working with? A short history of Child and Youth Care involvement with families. CYC Online, 103. Retrieved from http://www.cyc-net.org/ cyc-online/cycol-0708garfat.html.

Gershowitz, M., \& MacFarlane, A. (1990). The therapeutic potential of emergency shel ters. Child and Youth Services, 13, 95-103.

Harder, A. T., \& Knorth, E. J. (2015). Uncovering what is inside the black box of effective therapeutic residential youth care. Therapeutic residential care for children and youth Developing evidence-based international practice217-228.

Hawkins, S., Clinton-Sherrod, A., Irvin, N., Hart, L., \& Russell, S. (2009). Logic models as a tool for sexual violence prevention program development. Health Promotion Practice, 10, 29-37.

Hukkanen, R., Sourander, A., Bergroth, L., \& Piha, J. (1999). Psychosocial factors and adequacy of services for children in children's homes. European Child \& Adolescent Psychiatry, 8, 268-275.

Hurley, K. D., Ingram, S., Czyz, J. D., Juliano, N., \& Wilson, E. (2006). Treatment for youth in short-term care facilities: The impact of a comprehensive behavior management intervention. Journal of Child and Family Studies, 15(5), 615-630.

ISS - Instituto da Segurança Social (2010). Recomendações técnicas para equipamentos sociais - Centros de Acolhimento Temporário. Lisboa: ISS, I.P. [Retrieved from:] http:/ www.seg-social.pt/documents/10152/89982/rtes_centros_acolhimento_temporario/ 5050184e-1ceb-45dd-9815-4b3ad30a5a75.
James, S. (2011). What works in group care? A structured review of treatment models for group homes and residential care. Children and Youth Services Review, 33(2), 308-321.

Jozefiak, T., Kayed, N., Rimehaug, T., Wormdal, A., Brubakk, A., \& Wichstrøm, L. (2016). Prevalence and comorbidity of mental disorders among adolescents living in residential youth care. European Child \& Adolescent Psychiatry, 25, 33-47.

Knorth, E. J., Harder, A. T., Zandberg, T., \& Kendrick, A. J. (2008). Under one roof: A review and selective meta-analysis on the outcomes of residential child and youth care. Children and Youth Services Review, 30(2), 123-140.

Koehn, C. E., Thompson, R. W., Authier, K. J., \& Bosco, M. (2001). Palm Beach County child abuse and neglect system redesign: Initial process evaluation. Journal of Child and Family Studies, 10, 245-254.

Landy, S., \& Menna, R. (2009). Early intervention with multi-risk families: An integrative approach. Baltimore: Paul H. Brookes, publishing.

Lee, B. R. (2008). Defining residential treatment. Journal of Child and Family Studies, 17(5), 689-692.

Lei n.o. 142/2015. Diário da República - I Série n.o. 175 - 8 de setembro de 2015, pp. 7198-7232.

Leon, S. C., Jhe Bai, G., Fuller, A. K., \& Busching, M. (2016). Emergency shelter care utilization in child welfare: Who goes to shelter care? How long do they stay? American Journal of Orthopsychiatry, 86(1), 49.

Libby, A. M., Coen, A. S., Price, D. A., Silverman, K., \& Orton, H. D. (2005). Inside the Black Box: what constitutes a day in a residential treatment centre? International Journal of Social Welfare, 14(3), 176-183.

Liese, L. H., Anderson, J. L., \& Evans, R. P. (2004). The Christmas Box House: Developing a best practice model for emergency shelter care and assessment. Journal of Family Social Work, 7(3), 39-48.

Ministério do Trabalho e da Solidariedade Social [MTSS] (2006). Respostas Sociais Nomenclaturas/Conceitos. Lisboa: Direcção-Geral da Segurança Social, da Família e da Criança. Retrieved from: http://observatorio-lisboa.eapn.pt/ficheiro/Conceitos_das_ Respostas_Sociais.pdf.

Magalhães, E., \& Calheiros, M. M. (2017). A dual-factor model of mental health and socia support: Evidence with adolescents in residential care. Children and Youth Services Review, 79, 442-449.

McMillen, C., Auslander, W., Elze, D., White, T., \& Thompson, R. (2003). Educational experiences and aspirations of older youth in foster care. Child Welfare, 82(4), $475-495$.

Oakes, E. J., \& Freundlich, M. (2005). The role of emergency care as a child welfare service. CWLA Press.

Russel, J., \& Pratt, G. (1980). A description of the affective quality attributed to en vironments. Journal of Personality and Social Psychology, 38(2), 311-322.

Scott, J. (2000). Social network analysis: A handbook. London: Sage.

Souverein, F. A., Van der Helm, G. H. P., \& Stams, G. J. J. M. (2013). 'Nothing works' in secure residential youth care? Children and Youth Services Review, 35(12), 1941-1945.

Teufel-Shone, N. I., Siyuja, T., Watahomigie, H. J., \& Irwin, S. (2006). Community-based participatory research: Conducting a formative assessment of factors that influence youth wellness in the Hualapai community. American Journal of Public Health, 96(9), 1623-1628.

Turney, D., Platt, D., Selwyn, J., \& Farmer, E. (2011). Improving child and family assessments: Turning research into practice. Jessica Kingsley Publishers: London.

UNCRC (1989). United Nations convention on the rights of the child. [Retrieved from:] http://www2.ohchr.org/english/law/pdf/crc.pdf.

Van der Ploeg, J., \& Scholte, E. M. (1998). Job satisfaction in residential care. International Journal of Child and Family Welfare, 3(3), 228-241.

Wattenberg, E., Luke, K., \& Cornelius, M. (2004). Brief encounters: Children in shelter for 7 days or less. Children and Youth Services Review, 26(6), 591-607.

Joà Graca has a PhD in Psychology and is currently Postdoctoral Researcher at the Institute of Social Sciences (ICS), University of Lisbon. His research interests cover the design and evaluation of intervention programs for children and youth, and improving the social environment on developmental contexts such as schools and residential care settings. He is also interested in research on healthy, sustainable and ethical consumption.

Maria Manuela Calheiros has a $\mathrm{PhD}$ in Community Social Psychology and is currently Associate Professor at the Faculty of Psychology (FPUL), University of Lisbon. Her research interests cover the areas of education, well-being and risk factors associated to child and youth development; parental abuse and neglect; and the design and evaluation of intervention programs with abusive and neglectful families, and children and youth in residential care.

Joana Patrício has a MSc in Social and Organizational Psychology and works as psychologist in a kindergarten in Lisbon. She works as a practitioner but is also an active researcher whose interests include the evaluation of social services, and the development of measures and programs adjusted to the specific needs of children and youth.

Eunice Vieira Magalhaes has a PhD in Psychology and is Assistant Professor at the Universidade Lusófona de Humanidades e Tecnologias (Lisbon), Invited Assistant Professor at ISCTE-IUL, and Researcher at the CIS-IUL. Her research interests involve child protection, residential care services, victimology, psychological assessment, and evaluation and intervention with children and families at risk. 